Research Paper

\title{
Genetic polymorphisms may influence the vertical growth rate of melanoma
}

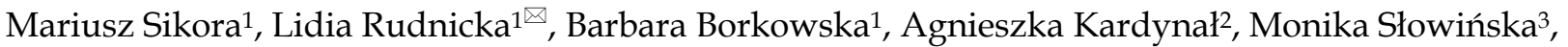 \\ Adriana Rakowska ${ }^{1}$, Olga Warszawik-Hendzel ${ }^{1}$, Anna Wiergowska ${ }^{2}$, Iwona Ługowska ${ }^{4}$, Piotr Rutkowski ${ }^{4}$, \\ Tadeusz Dębniak ${ }^{5}$, Jan Lubiński ${ }^{5}$, Małgorzata Olszewska ${ }^{1}$ \\ 1. Department of Dermatology, Medical University of Warsaw, 02-008 Warsaw, Poland \\ 2. Department of Dermatology, Central Clinical Hospital MSWiA, 02-507 Warsaw, Poland \\ 3. Department of Dermatology, Military Institute of Medicine, 04-141 Warsaw, Poland \\ 4. Department of Soft Tissue/Bone Sarcoma and Melanoma, Maria Sklodowska-Curie Memorial Cancer Center and Institute of Oncology, 02-781 Warsaw, \\ Poland \\ 5. Department of Genetics and Pathomorphology, Pomeranian Medical University, 70-111 Szczecin, Poland.
}

$\square$ Corresponding author: Lidia Rudnicka, MD, PhD, Professor and Chairman, Department of Dermatology, Medical University of Warsaw, Koszykowa 82A, 02-008 Warsaw, Poland. lidia.rudnicka@dermatolodzy.com.pl

(0) Ivyspring International Publisher. This is an open access article distributed under the terms of the Creative Commons Attribution (CC BY-NC) license (https:// creativecommons.org/licenses/by-nc/4.0/). See http://ivyspring.com/terms for full terms and conditions.

Received: 2018.03.31; Accepted: 2018.07.09; Published: 2018.08.06

\begin{abstract}
Background: Identification of new predictive markers in melanoma is of great clinical importance. This study was aimed to analyze association between selected common variants in the cancer susceptibility genes and melanoma progression at the time of diagnosis.

Material and Method: The study included 243 consecutive patients with melanoma. Genotyping was performed using real-time PCR.

Results: Our data revealed modest association between xeroderma pigmentosum complementation group D (XPD) codon 312 polymorphism and tumor thickness (as defined by Breslow score; XPD D312N CC: $3.00 \pm 3.78 \mathrm{~mm}, \mathrm{CT}: 1.71 \pm 2.48 \mathrm{~mm}$, TT: $2,53 \pm 3,24 \mathrm{~mm}, \mathrm{P}=0.023$ ). The CT genotype in XPD D3 $12 \mathrm{~N}$ polymorphism was more frequently represented in non-invasive melanomas compared to deeply penetrating tumors. None of the common SNPs in cyclin dependent kinase inhibitor 2A (CDKN2A), vitamin D receptor (VDR), melanocortin 1 receptor (MCIR) were associated with Breslow depth.

Conclusion: These findings suggest that genetic alteration in XPD contributes to melanoma progression and may be a potential diagnostic and molecular prognostic marker.
\end{abstract}

Key words: CDKN2A, MC1R, cutaneous melanoma, polymorphism, VDR, XPD.

\section{Introduction}

Melanoma is considered one of the most aggressive neoplasms with extremely poor prognosis at advanced stages. The worldwide incidence and mortality rates of this tumor have been increasing over the last decades [1]. A combination of clinical criteria and histopathological features are established methods used for melanoma staging and predicting the survival outcome [2]. The most important prognostic factors include tumor thickness, ulceration, Clark level, mitotic rate and status of the sentinel lymph node. However, these markers are limited in their ability to reliably distinguish between low and high-risk melanoma cases [3]. Therefore, there is an urgent need to further sub-classify and identify new prognostic biomarkers to improve prediction and develop new targets for therapy.

Although exposure to ultraviolet (UV) radiation is a major environmental risk factor for melanoma, the genetic factors contribute to the development and progression of the disease. The malignant transformation from melanocytes to melanoma and the progression of primary cutaneous tumors to invasive and metastatic diseases results from a combination of genetic alterations [4]. 
A number of recent genome wide association studies have confirmed several regions associated with cancer initiation and development [5]. Melanoma risk is attributable to rare germline or somatic mutations in a variety of tumor suppressor genes such as CDKN2A [6], nucleotide excision repair system [7] and many other low-penetrant genetic variants that include melanocortin-1 receptor (MC1R) [8] or vitamin D receptor (VDR) [9]. There is a growing list of candidate genes that have been speculated to be involved in molecular mechanism behind melanoma formation. However, relatively little is known about genetic factors for melanoma progression and metastasis.

Thus, the aim of our study was to evaluate whether polymorphisms in genes previously associated with the increased risk of melanoma play an essential role in tumor progression. Genetic alterations selected for analysis included seven single nucleotide polymorphisms in the common variants of following four genes: CDKN2A (A148T), XPD (D312N, K751Q), VDR (M1T), MC1R (R160W, R151C, R163Q).

\section{Material and Methods}

\section{Melanoma patients}

We studied a group of 243 consecutive patients with newly diagnosed and histologically confirmed cutaneous melanoma. The study included 135 women and 108 men with a mean age at diagnosis of 49.2 years (age range: 19-83), diagnosed at four major skin cancer centres in Warsaw, Poland.

All participants signed an informed consent document before entering the study. The participation rate was $99,2 \%$. The study was approved by the local ethics committee.

\section{Genotyping}

Genotyping was performed in DNA samples isolated from peripheral blood cells of patients with melanoma. Molecular analysis was performed using a combination of real-time PCR (LightCycler 480, Roche, Penzberg, Germany) and MassARRAY MALDI-TOF MS analysis (Sequenom Inc., San Diego, CA, USA). For real-time PCR TaqMan genotyping assays were used (Applied Biosystems, Foster City, CA). MALDI-TOF analysis was based on a primer extension reaction to detect and determine the SNP allele. Reactions were performed according to the manufacturer's instructions.

\section{Sequencing}

Random DNA samples were sequenced to verify the results of the MassARRAY genotyping and real-time PCR analysis. Sequencing was conducted using universal primers in combination with the ABI PRISM BigDye Terminator Cycle (Applied Biosystems, Foster City, CA) in the 3130 Genetic Analyzer (Applied Biosystems, Foster City, CA).

SNP selection, experimental conditions to perform RFLP-PCRs, real time PCR and DNA sequencing have been described previously [10-12].

\section{Duration of skin lesion prior to diagnosis}

The duration of the lesion diagnosed as melanoma prior to diagnosis was based on detailed anamnesis in all patients.

\section{Statistical methods}

Data are presented as mean \pm SD. Associations between polymorphisms and clinicopathological features of melanoma patients were analysed by Mann-Whitney U-test for single comparisons and with Kruskal-Wallis test, followed by Dunn's post hoc test for multiple comparisons. To determine significant differences of genotype frequencies in patients with tumor Breslow thickness $\leq 1 \mathrm{~mm}$ or $>$ $1 \mathrm{~mm}$ two-tailed Fisher exact test was used. All statistical analyses were performed using STATISTICA 12.0 (StatSoft, Krakow, Poland). P-values $<0.05$ were considered statistically significant.

\section{Results}

\section{Breslow thickness}

The comparison of mean tumor Breslow depth between carriers of each analyzed single nucleotide polymorphism (SNP) (Table 1) revealed that the D312N CT genotype was more frequent in patients with thinner tumor thickness $(\mathrm{P}=0.023)$ compared to $\mathrm{CC}$ and TT genotypes. We further analyzed allele distribution in subgroups of melanoma patients with Breslow thickness $\leq 1 \mathrm{~mm}$ and $>1 \mathrm{~mm}$ (Table 2 ) as well as patients with invasive and in situ cancer (Table 3). The CT genotype in XPD D312N polymorphism was more frequently represented in non-invasive melanomas compared to thicker and more deeply penetrating tumors. Since XPD gene plays an important role in the removal of UV-light-induced DNA damage we investigated correlations between XPD D312N polymorphisms and Fitzpatrick skin phototype, melanoma location (sun-exposed areas vs sun-hidden locations), number of melanocytic nevi or sunburns in anamnesis. However, we did not find any association between this clinical variables and investigated polymorphism (Table 4).

\section{Time of lesion duration before diagnosis}

As shown in Table 5, the presence of the A148T CDKN2A polymorphism was more likely to be 
diagnosed in patients with pigmented skin lesions that run a shorter course $(\mathrm{P}=0.012)$ compared to melanoma patients without this variant. We found no association between common XPD, MC1R, VDR variants and duration of skin lesion prior to diagnosis.

\section{Age at diagnosis and sex}

There were no statistically significant differences in the mean age at diagnosis as well as sex between the subjects carrying the examined SNPs (data not shown).

Table 1. Association between gene polymorphisms and Breslow thickness

\begin{tabular}{llll}
\hline SNP & Genotype & $\begin{array}{l}\text { Mean Breslow } \\
\text { thickness }\end{array}$ & P value \\
\hline VDR M1T & AA $(\mathrm{n}=34)$ & $2,78 \pm 3,36$ & - \\
& GA $(\mathrm{n}=89)$ & $2,40 \pm 3,61$ & NS \\
XPD D312N & GG $(\mathrm{n}=49)$ & $2,25 \pm 2,13$ & NS \\
& CC $(\mathrm{n}=54)$ & $3,00 \pm 3,78$ & - \\
XPD K751Q & CT $(\mathrm{n}=56)$ & $1,71 \pm 2,48$ & $\mathbf{0 , 0 2 3}$ \\
& TT $(\mathrm{n}=51)$ & $2,53 \pm 3,24$ & NS \\
MC1R R151C & GT $(\mathrm{n}=23)$ & $2,00 \pm 1,90$ & - \\
rs1805007 & TT $(\mathrm{n}=68)$ & $2,32 \pm 3,19$ & NS \\
MC1R V60L & CC $(\mathrm{n}=155)$ & $2,63 \pm 3,59$ & NS \\
rs1805005 & CT $(\mathrm{n}=14)$ & $2,48 \pm 3,15$ & - \\
& GG $(\mathrm{n}=148)$ & $2,59 \pm 3,96$ & NS \\
MC1R R163Q & GT $(\mathrm{n}=21)$ & $2,28 \pm 2,01$ & - \\
rs885479 & GG $(\mathrm{n}=161)$ & $2,37 \pm 3,22$ & NS \\
CDKN2A A148T & PG $(\mathrm{n}=11)$ & $3,57 \pm 2,83$ & NS \\
& Positive $(\mathrm{n}=8)$ & $2,70 \pm 1,68$ & - \\
\hline
\end{tabular}

NS - Not Statistically Significant

Table 2. Allele distribution in melanoma patients with Breslow thickness $\leq 1 \mathrm{~mm}$ and $>1 \mathrm{~mm}$

\begin{tabular}{|c|c|c|c|c|}
\hline SNP & Genotype & $\begin{array}{l}\text { Breslow } \\
(\leq 1 \mathrm{~mm})\end{array}$ & $\begin{array}{l}\text { Breslow } \\
(>1 \mathrm{~mm})\end{array}$ & P value \\
\hline \multirow[t]{3}{*}{ VDR M1T } & AA $(n=34)$ & $15(44,1 \%)$ & $19(55,9 \%)$ & - \\
\hline & GA $(n=89)$ & $32(36 \%)$ & $57(64 \%)$ & NS \\
\hline & GG $(n=49)$ & $17(34,7 \%)$ & $32(65,3 \%)$ & NS \\
\hline \multirow[t]{3}{*}{ XPD D312N } & $C C(n=54)$ & $15(27,8 \%)$ & $39(72,2 \%)$ & - \\
\hline & $\mathrm{CT}(\mathrm{n}=56)$ & $26(46,4 \%)$ & $30(53,6 \%)$ & - \\
\hline & $\mathrm{TT}(\mathrm{n}=51)$ & $20(39,2 \%)$ & $31(60,8 \%)$ & NS \\
\hline \multirow[t]{3}{*}{ XPD K751Q } & GG $(n=23)$ & $9(39,1 \%)$ & $14(60,9 \%)$ & - \\
\hline & GT $(n=79)$ & $32(40,5 \%)$ & $47(59,5 \%)$ & NS \\
\hline & $\mathrm{TT}(\mathrm{n}=68)$ & $24(35,3 \%)$ & $44(64,7 \%)$ & NS \\
\hline \multirow{2}{*}{$\begin{array}{l}\text { MC1R R151C } \\
\text { rs1805007 }\end{array}$} & $C C(n=155)$ & $55(35,5 \%)$ & $100(64,5 \%)$ & - \\
\hline & $\mathrm{CT}(\mathrm{n}=14)$ & $6(42,9 \%)$ & $8(57,1 \%)$ & NS \\
\hline \multirow{2}{*}{$\begin{array}{l}\text { MC1R V60L } \\
\text { rs1805005 }\end{array}$} & GG $(n=148)$ & $57(38,5 \%)$ & $91(61,5 \%)$ & - \\
\hline & GT $(n=21)$ & $6(28,6 \%)$ & $15(71,4 \%)$ & NS \\
\hline \multirow{2}{*}{$\begin{array}{l}\text { MC1R R163Q } \\
\text { rs885479 }\end{array}$} & GG $(n=161)$ & $59(36,6 \%)$ & $102(63,4 \%)$ & - \\
\hline & $\mathrm{AG}(\mathrm{n}=11)$ & $4(36,4 \%)$ & $7(63,6 \%)$ & NS \\
\hline \multirow{2}{*}{$\begin{array}{l}\text { CDKN2A } \\
\text { A148T }\end{array}$} & Positive $(n=8)$ & $1(12,5 \%)$ & $7(87,5 \%)$ & - \\
\hline & $\begin{array}{l}\text { Negative } \\
(\mathrm{n}=165)\end{array}$ & $58(35,2 \%)$ & $107(64,8 \%)$ & NS \\
\hline
\end{tabular}

NS - Not Statistically Significant
Table 3. Allele distribution in patients with in situ and invasive melanoma.

\begin{tabular}{|c|c|c|c|c|}
\hline SNP & Genotype & Tumor in situ & Invasive & $P$ value \\
\hline \multirow[t]{3}{*}{ VDR M1T } & $\mathrm{AA}(\mathrm{n}=30)$ & $3(10 \%)$ & $27(90 \%)$ & - \\
\hline & GA $(n=85)$ & $13(15,3 \%)$ & $72(84,3 \%)$ & - \\
\hline & GG $(n=46)$ & $6(13,1 \%)$ & $40(86,9 \%)$ & NS \\
\hline \multirow[t]{3}{*}{ XPD D312N } & $\mathrm{CC}(\mathrm{n}=48)$ & $4(8,3 \%)$ & $44(91,7 \%)$ & - \\
\hline & $\mathrm{CT}(\mathrm{n}=52)$ & $13(25 \%)$ & $39(75 \%)$ & 0,038 \\
\hline & $\mathrm{TT}(\mathrm{n}=49)$ & $5(10,2 \%)$ & $44(89,8 \%)$ & - \\
\hline \multirow[t]{3}{*}{ XPD K751Q } & GG $(n=21)$ & $2(9,5 \%)$ & $19(90,5 \%)$ & - \\
\hline & GT $(n=76)$ & $8(10,5 \%)$ & $68(89,5 \%)$ & - \\
\hline & $\mathrm{TT}(\mathrm{n}=62)$ & $13(21,0 \%)$ & $49(79,0 \%)$ & NS \\
\hline \multirow{2}{*}{$\begin{array}{l}\text { MC1R R151C } \\
\text { rs1805007 }\end{array}$} & $\mathrm{CC}(\mathrm{n}=149)$ & $19(12,8 \%)$ & $130(87,2 \%)$ & - \\
\hline & $\mathrm{CT}(\mathrm{n}=12)$ & $3(25 \%)$ & $9(75 \%)$ & NS \\
\hline \multirow{2}{*}{$\begin{array}{l}\text { MC1R V60L } \\
\text { rs1805005 }\end{array}$} & GG $(n=139)$ & $19(13,7 \%)$ & $120(86,3 \%)$ & - \\
\hline & GT $(n=21)$ & $2(9,5 \%)$ & $19(90,5 \%)$ & NS \\
\hline \multirow{2}{*}{$\begin{array}{l}\text { MC1R R163Q } \\
\text { rs885479 }\end{array}$} & GG $(n=153)$ & $22(14,4 \%)$ & $131(85,6 \%)$ & - \\
\hline & $\mathrm{AG}(\mathrm{n}=10)$ & $1(10 \%)$ & $9(90 \%)$ & NS \\
\hline \multirow{2}{*}{$\begin{array}{l}\text { CDKN2A } \\
\text { A148T }\end{array}$} & Positive $(\mathrm{n}=8)$ & $1(14,3 \%)$ & $7(83,7 \%)$ & - \\
\hline & $\begin{array}{l}\text { Negative } \\
(n=157)\end{array}$ & $25(15,9 \%)$ & $132(84,1 \%)$ & NS \\
\hline
\end{tabular}

Table 4. Clinical characteristic of patients with XPD D312N polymorphism

\begin{tabular}{lllll}
\hline Clinical variable & $\mathrm{CC}(\mathrm{n}=75)$ & $\mathrm{CT}(\mathrm{n}=72)$ & $\mathrm{TT}(\mathrm{n}=72)$ \\
\hline skin phototype & I & $11(14.7 \%)$ & $10(13.9 \%)$ & $10(13.9 \%)$ \\
& II & $44(58.7 \%)$ & $43(59.7 \%)$ & $41(56.9 \%)$ \\
& III & $16(21.3 \%)$ & $15(20.8 \%)$ & $18(25.0 \%)$ \\
& IV & $4(5.3 \%)$ & $4(5.6 \%)$ & $3(4.2 \%)$ \\
melanoma & sun-exposed & $17(22.6 \%)$ & $16(22.2 \%)$ & $15(20.8 \%)$ \\
location & areas & & & \\
& sun-hidden & $58(77.3 \%)$ & $56(77.8 \%)$ & $57(79.2 \%)$ \\
number of & locations & & & \\
melanocytic & $<10$ & $21(28.0 \%)$ & $22(30.6 \%)$ & $20(27.8 \%)$ \\
nevi & $10-50$ & $21(28.0 \%)$ & $23(31.9 \%)$ & $26(36.1 \%)$ \\
& $51-100$ & $14(18.7 \%)$ & $11(15.3 \%)$ & $10(13.9 \%)$ \\
sunburn in & $>100$ & $19(25.3 \%)$ & $16(22.2 \%)$ & $16(22.2 \%)$ \\
childhood & first-degree & $51(68.0 \%)$ & $48(66.7 \%)$ & $47(65.3 \%)$ \\
\hline
\end{tabular}

Table 5. Association between gene polymorphisms and time of lesion duration

\begin{tabular}{llll}
\hline SNP & Genotype & $\begin{array}{l}\text { Time of lesion } \\
\text { duration (months) }\end{array}$ & P value \\
\hline VDR M1T & AA $(\mathrm{n}=28)$ & $8,88 \pm 17,21$ & - \\
& GA $(\mathrm{n}=84)$ & $6,21 \pm 12,01$ & NS \\
XPD D312N & GG $(\mathrm{n}=50)$ & $7,24 \pm 14,01$ & NS \\
& CC $(\mathrm{n}=56)$ & $8,52 \pm 15,38$ & - \\
& CT $(\mathrm{n}=51)$ & $7,30 \pm 13,52$ & NS \\
XPD K751Q & TT $(\mathrm{n}=46)$ & $5,26 \pm 9,79$ & NS \\
& GG $(\mathrm{n}=24)$ & $7,46 \pm 15,58$ & - \\
& GT $(\mathrm{n}=70)$ & $6,50 \pm 12,39$ & NS \\
MC1R R151C & TT $(\mathrm{n}=66)$ & $7,48 \pm 14,39$ & NS \\
rs1805007 & CC $(\mathrm{n}=143)$ & $7,03 \pm 14,04$ & - \\
& & & \\
MC1R V60L & CT $(\mathrm{n}=17)$ & $8,03 \pm 10,72$ & NS \\
rs1805005 & GG $(\mathrm{n}=138)$ & $6,70 \pm 11,88$ & - \\
& & & \\
MC1R R163Q & GT $(\mathrm{n}=24)$ & $7,35 \pm 18,34$ & NS \\
rs885479 & GG $(\mathrm{n}=151)$ & $7,45 \pm 14,03$ & - \\
& & & \\
CDKN2A A148T & AG $(\mathrm{n}=13)$ & $2,85 \pm 3,48$ & NS \\
& Positive $(\mathrm{n}=7)$ & $0,79 \pm 0,99$ & - \\
& Negative (n=157) & $7,34 \pm 13,79$ & $\mathbf{0 , 0 1 2}$ \\
\hline
\end{tabular}

NS - Not Statistically Significant 


\section{Discussion}

In the current study molecular analysis of 7 polymorphisms in 4 melanoma susceptibility genes showed a significant association between XPD D312N polymorphism and depth of invasion measured by Breslow thickness. Tumor thickness is considered the most important prognostic factor [13]. Numerous studies demonstrated that Breslow thickness, of all histopathological parameters, presents the strongest correlation with survival rates [14].

One potential mechanism to explain our findings could be that $\mathrm{D} 312 \mathrm{~N}$ polymorphism may result in protein folding modification and thus affect the protein function [15]. The XPD gene plays an important role in the maintenance of genomic integrity by removing UV-light-induced DNA lesions [16]. The XPD gene product is a DNA helicase involved in transcription, repair of DNA damage, cell cycle regulation and chromosome segregation [17, 18]. Hereditary defects in the XPD gene can result in high susceptibility to carcinogenesis [17]. Individual variations in XPD activity also may be a possible cancer risk factor. Several single nucleotide polymorphisms that induce amino acid changes have been described in XPD including codons 199 (Ile to Met), 201 (His to Tyr), 312 (Asp to Asn) and 751 (Lys to Gln) [19]. The first two are quite rare in most populations, whereas polymorphism in codon 312 and 751 have been associated with p53 gene mutation and cancer risk [20]. The XPD D312N polymorphism may result in the removal of the acidic moiety of aspartic acid, which can alter protein folding and interactions [19]. The amino acid substitution could result in different enzyme activity and repair capacity. Thus, association between the XPD polymorphism and cancer risk as well as progression is biologically plausible.

There are many reports indicating involvement of XPD gene polymorphisms in melanoma risk [7, 21]. However, only two studies have investigated the association of this gene with cancer progression. Kertat et al. examined the codon 751 polymorphism at the XPD gene in 244 melanoma patients in the Swedish population [22]. The authors found that heterozygous form (Lys/Gln) was more frequent in melanomas with Breslow thickness of $>1.5 \mathrm{~mm}$ and the Clark levels III and IV, thus indicating a predictive role for XPD. The second investigation by Liu et al., conducted in 90 patients with stage IV melanoma failed to find an association between K751Q and prognostic variables and clinical outcomes [23]. No data on XPD D312N polymorphism was provided in these two studies. Similarly to our results, additional investigations showed predictive value of $\mathrm{XPD}$
D312N polymorphism in patients with non-small cell lung cancer [24, 25].

Another interesting observation rising from this study is that the presence of a CDKN2A A148T variant was more likely to be diagnosed in patients with shorter history of melanoma development compared to group without this polymorphism. The CDKN2A (OMIM 600160) is a tumor suppressor gene that encodes the p16 protein - a cyclin dependent kinase inhibitor and suppressor of cell proliferation [26]. An alanine to threonine substitution at codon 148 (A148T) is a common variant of CDKN2A, which is present in approximately $3.5 \%$ of the general population in Poland and have been shown to predispose to melanoma [10]. Reports assessing the association of A148T CDKN2A polymorphism with the p16 function are inconclusive. Some reports indicate that CDKN2A A148T variant do not alter protein function [27], whereas others studies show that the A148T variant is in strong linkage disequilibrium with a promoter polymorphism P493 and indirectly affects p16 function and reduces its expression [28]. Nevertheless, A148T is considered a molecular risk factor for developing several malignancies such as melanoma, breast or lung cancer [28]. Moreover, the loss of p16 expression in patients with vertical growth phase melanoma is associated with melanoma aggressiveness, increased tumor cell proliferation and reduced patient survival [29]. Our observation that A148T CDKN2A polymorphism is related to shorter clinical onset is also of clinical relevance, particularly for its prognostic implications. However, additional studies are required to determine whether this particular polymorphism can be associated with melanoma progression.

Genetic variants for the melanocortin-1 receptor (MC1R) gene have been found to be associated with the increased risk of melanoma development via pigmentary and non-pigmentary pathways [10, 30]. All SNPs in MC1R that were examined in this study did not appear to correlate significantly with tumor progression markers. Our findings are consistent with a study by Taylor et al., who did not observe any association of MC1R genotypes with Breslow thickness, tumor site and age at first diagnosis [31]. The major limitation in both studies is high polymorphism at the MC1R locus [32].

The role of VDR polymorphisms and melanoma progression remains controversial. In accordance with previous studies [33], no correlation was found between VDR genotype and Breslow thickness. Some reports demonstrate VDR gene polymorphism association with outcome in melanoma patients [34]. However, it remains necessary to determine that observed effects was related to impaired VDR protein 
function rather than decreased VDR expression or vitamin D deficiency.

A limitation of our study is the relatively small samples size. Therefore, further studies taking into account heterogeneous nature of melanoma are required to confirm the findings and to better understand the role of genetic factors in cancer progression.

In conclusion, our results suggest that the XPD D312N polymorphism demonstrated a significant association with tumor thickness and may be a prognostic marker.

\section{Acknowledgements}

The authors thank all general practitioners, dermatologists and oncologists, who referred patients to us. This work was supported by the National Science Centre under Grant no. N N404 517838.

\section{Competing Interests}

The authors have declared that no competing interest exists.

\section{References}

1. Sacchetto L, Zanetti R, Comber H, Bouchardy C, Brewster DH, Broganelli $\mathrm{P}$, et al. Trends in incidence of thick, thin and in situ melanoma in Europe. European journal of cancer. 2018; 92: 108-18.

2. Gershenwald JE, Scolyer RA, Hess KR, Sondak VK, Long GV, Ross MI, et al. Melanoma staging: Evidence-based changes in the American Joint Committee on Cancer eighth edition cancer staging manual. CA Cancer J Clin. 2017; 67: 472-92

3. Botella Estrada R, Escutia Munoz B. Staging and follow-up of patients with melanoma: which tests for which patients? Actas dermo-sifiliograficas. 2014; 105: 531-4.

4. Testa U, Castelli G, Pelosi E. Melanoma: Genetic Abnormalities, Tumor Progression, Clonal Evolution and Tumor Initiating Cells. Med Sci (Basel). 2017; 5

5. Ransohoff KJ, Wu W, Cho HG, Chahal HC, Lin Y, Dai HJ, et al. Two-stage genome-wide association study identifies a novel susceptibility locus associated with melanoma. Oncotarget. 2017; 8: 17586-92.

6. Aspinwall LG, Stump TK, Taber JM, Drummond DM, Kohlmann W, Champine $M$, et al. Genetic test reporting of CDKN2A provides informational and motivational benefits for managing melanoma risk. Transl Behav Med. 2018; 8: 29-43.

7. Paszkowska-Szczur K, Scott RJ, Serrano-Fernandez P, Mirecka A, Gapska P, Gorski B, et al. Xeroderma pigmentosum genes and melanoma risk. International journal of cancer Journal international du cancer. 2013; 133: 1094-100.

8. Kanetsky PA, Hay JL. Marshaling the Translational Potential of MC1R for Precision Risk Assessment of Melanoma. Cancer Prev Res (Phila). 2018; 11: 121-4.

9. Cauci S, Maione V, Buligan C, Linussio M, Serraino D, Stinco G. BsmI (rs1544410) and FokI (rs2228570) vitamin D receptor polymorphisms, smoking, and body mass index as risk factors of cutaneous malignant melanoma in northeast Italy. Cancer Biol Med. 2017; 14: 302-18.

10. Debniak T, Scott R, Masojc B, Serrano-Fernandez P, Huzarski T, Byrski T, et al. MC1R common variants, CDKN2A and their association with melanoma and breast cancer risk. International journal of cancer Journal international du cancer. 2006; 119: 2597-602.

11. Paszkowska-Szczur K, Scott RJ, Gorski B, Cybulski C, Kurzawski G, Dymerska D, et al. Polymorphisms in nucleotide excision repair genes and susceptibility to colorectal cancer in the Polish population. Mol Biol Rep. 2015; 42: 755-64

12. Gromowski T, Gapska P, Scott RJ, Kaklewski K, Marciniak W, Durda K, et al. Serum $25(\mathrm{OH}) \mathrm{D}$ concentration, common variants of the VDR gene and lung cancer occurrence. International journal of cancer Journal international du cancer. 2017; 141: 336-41.
13. Rutkowski P, J. Wysocki P, Nasierowska-Guttmejer A, Fijuth J, Kalinka-Warzocha E, Świtaj T, et al. Czerniaki skóry - zasady postępowania diagnostyczno-terapeutycznego w 2016 roku. Dermatology Review/Przegląd Dermatologiczny. 2016; 103: 1-18.

14. Lo SN, Scolyer RA, Thompson JF. Long-Term Survival of Patients with Thin (T1) Cutaneous Melanomas: A Breslow Thickness Cut Point of 0.8 mm Separates Higher-Risk and Lower-Risk Tumors. Annals of surgical oncology. 2018; 25: 894-902.

15. Affatato AA, Wolfe KJ, Lopez MS, Hallberg C, Ammenheuser MM, Abdel-Rahman SZ. Effect of XPD/ERCC2 polymorphisms on chromosome aberration frequencies in smokers and on sensitivity to the mutagenic tobacco-specific nitrosamine NNK. Environmental and molecular mutagenesis. 2004; 44: 65-73.

16. Sugasawa K. Molecular mechanisms of DNA damage recognition for mammalian nucleotide excision repair. DNA Repair (Amst). 2016; 44: 110-7.

17. Sameer AS, Nissar S. XPD-The Lynchpin of NER: Molecule, Gene, Polymorphisms, and Role in Colorectal Carcinogenesis. Front Mol Biosci. 2018; 5: 23.

18. Houten BV, Kuper J, Kisker C. Role of XPD in cellular functions: To TFIIH and beyond. DNA Repair (Amst). 2016; 44: 136-42.

19. Benhamou S, Sarasin A. ERCC2/XPD gene polymorphisms and cancer risk. Mutagenesis. 2002; 17: 463-9.

20. Mechanic LE, Marrogi AJ, Welsh JA, Bowman ED, Khan MA, Enewold L, et al. Polymorphisms in XPD and TP53 and mutation in human lung cancer. Carcinogenesis. 2005; 26: 597-604.

21. Wu KG, He XF, Li YH, Xie WB, Huang X. Association between the XPD/ERCC2 Lys751Gln polymorphism and risk of cancer: evidence from 224 case-control studies. Tumour Biol. 2014; 35: 11243-59.

22. Kertat K, Rosdahl I, Sun XF, Synnerstad I, Zhang H. The Gln/Gln genotype of XPD codon 751 as a genetic marker for melanoma risk and Lys/Gln as an important predictor for melanoma progression: a case control study in the Swedish population. Oncology reports. 2008; 20: 179-83.

23. Liu D, O'Day SJ, Yang D, Boasberg P, Milford R, Kristedja T, et al. Impact of gene polymorphisms on clinical outcome for stage IV melanoma patients treated with biochemotherapy: an exploratory study. Clinical cancer research : an official journal of the American Association for Cancer Research. 2005; 11: 1237-46.

24. Zhang L, Ma W, Li Y, Wu J, Shi GY. Pharmacogenetics of DNA repair gene polymorphisms in non-small-cell lung carcinoma patients on platinum-based chemotherapy. Genetics and molecular research : GMR. 2014; 13: 228-36.

25. Zhou M, Ding YJ, Feng Y, Zhang QR, Xiang Y, Wan HY. Association of xeroderma pigmentosum group D (Asp312Asn, Lys751Gln) and cytidine deaminase (Lys27Gln, Ala70Thr) polymorphisms with outcome in Chinese non-small cell lung cancer patients treated with cisplatin-gemcitabine. Genetics and molecular research : GMR. 2014; 13: 3310-8.

26. Zhao R, Choi BY, Lee MH, Bode AM, Dong Z. Implications of Genetic and Epigenetic Alterations of CDKN2A (p16(INK4a)) in Cancer. EBioMedicine. 2016; 8: 30-9.

27. Ranade K, Hussussian CJ, Sikorski RS, Varmus HE, Goldstein AM, Tucker MA, et al. Mutations associated with familial melanoma impair p16INK4 function. Nature genetics. 1995; 10: 114-6.

28. Debniak T, Scott RJ, Huzarski T, Byrski T, Rozmiarek A, Debniak B, et al. CDKN2A common variant and multi-organ cancer risk--a population-based study. International journal of cancer Journal international du cancer. 2006; 118: 3180-2

29. Young RJ, Waldeck K, Martin C, Foo JH, Cameron DP, Kirby L, et al. Loss of CDKN2A expression is a frequent event in primary invasive melanoma and correlates with sensitivity to the CDK4/6 inhibitor PD0332991 in melanoma cell lines. Pigment cell \& melanoma research. 2014; 27: 590-600.

30. Herraiz C, Garcia-Borron JC, Jimenez-Cervantes C, Olivares C. MC1R signaling. Intracellular partners and pathophysiological implications. Biochim Biophys Acta. 2017; 1863: 2448-61.

31. Taylor NJ, Reiner AS, Begg CB, Cust AE, Busam KJ, Anton-Culver H, et al. Inherited variation at $\mathrm{MC1R}$ and ASIP and association with melanoma-specific survival. International journal of cancer Journal international du cancer. 2015; 136: 2659-67.

32. Motorina AV, Palkina NV, Komina AV, Ruksha TG, Artyukhov IP, Kozlov VV. Genetic analysis of melanocortin 1 receptor red hair color variants in a Russian population of Eastern Siberia. Eur J Cancer Prev. 2018; 27: 192-6

33. Luo L, Orlow I, Kanetsky PA, Thomas NE, Fang S, Lee JE, et al. No prognostic value added by vitamin D pathway SNPs to current prognostic system for melanoma survival. PLoS One. 2017; 12: e0174234. 
34. Orlow I, Reiner AS, Thomas NE, Roy P, Kanetsky PA, Luo L, et al. Vitamin D receptor polymorphisms and survival in patients with cutaneous melanoma: a population-based study. Carcinogenesis. 2016; 37: $30-8$. 